Access to this work was provided by the University of Maryland, Baltimore County (UMBC)

ScholarWorks@UMBC digital repository on the Maryland Shared Open Access (MD-SOAR) platform.

Please provide feedback

Please support the ScholarWorks@UMBC repository by emailing scholarworks-group@umbc.edu and telling us what having access to this work means to you and why it's important to you. Thank you. 


\section{Full-Day Kindergarten and Later Reading: The Role of Early Reading Skills}

Joy A. Thompson \& Susan Sonnenschein

University of Maryland, Baltimore County

Department of Psychology

APA 2011

\section{INTRODUCTION}

$>$ Approximately $74 \%$ of children attend Full-Day Kindergarten (U.S. Department of Commerce, 2011).

$>$ Full-Day Kindergarten is viewed as beneficial because of the additional time in school. In fact, children in Full-Day Kindergarten spend $1 / 3$ more time in literacy activities than children in Half-Day Kindergarten (Lee, Burkam, Ready, Honigman, \& Meisels, 2006). This can these programs (Walston \& West, 2004).

Research consistently finds that Full-Day Kindergarten children earn higher reading cores at the end of kindergarten than those in Hall-Day (Baskett, Bryant, White, \& Rhoads, 2005; Votruba-Drzal, Lig-Grining, \& Maldonado-Carreno, 2008; Yan \& Lin, 2005). However, the beneft fades shortly after kindergarten (Rathbun \& West, 2004; Walston, West, \& Rathbun, 2005).

- The present study examines the immediate and long-term benefits of Full-Day Kindergarten, but takes a different methodological approach than previous research. Kindergarten, but takes a different methodological approach than previous researc
Instead of only comparing reading scores of Full- and Half-Day children in the elementary grades, the specific reading skills children acquire in kindergarten are considered.

It is important to consider early reading skills, as reading research highlights the mportance of these skills for later reading (Morris, Bloodgood, \& Perney, 2003; Scanlon \& Vellutino, 1996)

For example, low-SES children who attain early word reading skills by first gradeletter knowledge, beginning sounds, ending sounds, and sight words---perform comparably to higher-SES counterparts (Kaplan \& Walpole, 2005). However, research has not examined whether these gains last beyond first grade.

PURPOSE

To compare Full- and Half-Day children's early word reading attainment at the end of kindergarten.

To examine whether early word reading attainment at the end of kindergarten mediates relation between Full-Day Kindergarten attendance and later reading.

\section{\begin{tabular}{l|l} 
Participants & METHOD
\end{tabular}}

- Data came from Early Childhood Longitudinal Study-Kindergarten cohort (ECLS-K), a national study which followed approximately 21,000 children from kindergarten through fifth grade.

-Included in the present study were children who met the following criteria - Public school

First-time kindergarteners

ols during kindergarten

-Attended kindergarten 5 day/week

Averest at time points of interest

Inclusion criteria yielded $N=4,764$

.49\% Male

African American, $15 \%$ Hispanic 94\% English speaking

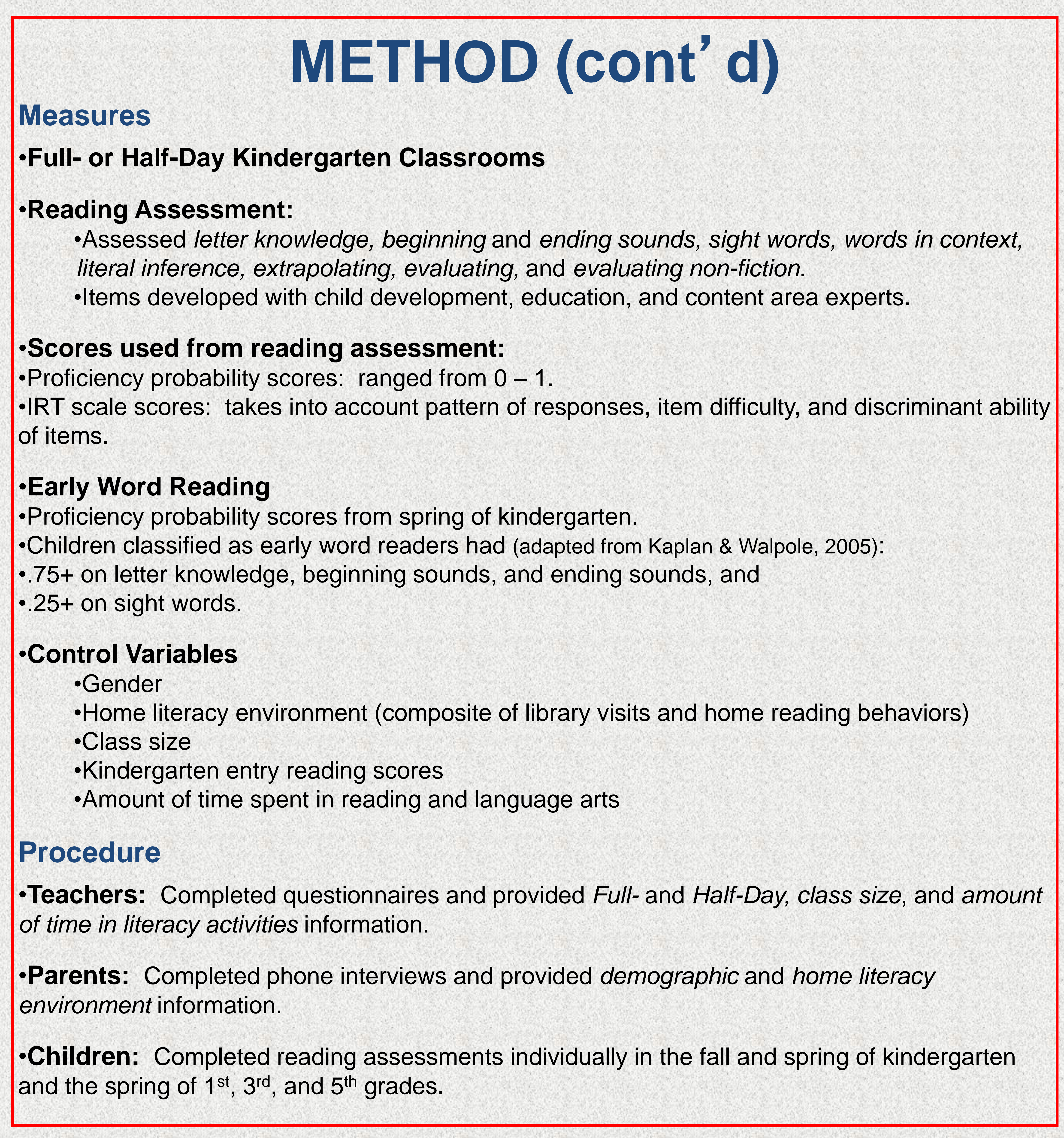

\section{RESULTS}

Full-Day Kindergarten is Beneficia

-Full-Day Kindergarten attendance predicted end-of-kindergarten early word reading

-OR $=2.13, \chi^{2}(1, N=4,614)=12.45, p<.001,95 \% \mathrm{Cl}[1.40,3.23]$

Early Word Reading Attainment as Mediator

- Early word reading at the end of kindergarten, in turn, predicted IRT reading scores in $1^{\text {st }} 3^{\text {rd }}$ and $5^{\text {th }}$ grades.

-Full-Day Kindergarten children had first grade reading scores 10.16 scale score points higher than Half-Day Kindergarten children.

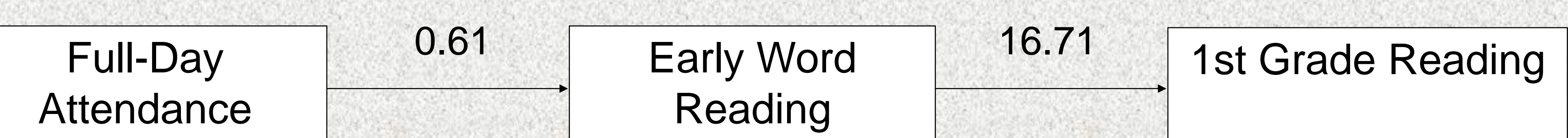

Note. $95 \% \mathrm{Cl}[2.59,17.72]$, size of mediated effect ranges from .12 to .82 .

\section{RESULTS (cont' d)}

- Full-Day Kindergarten children had third grade reading scores 8.04 scale score points higher than Half-Day Kindergarten children.

\begin{tabular}{|c|c|c|c|c|}
\hline $\begin{array}{c}\text { Full-Day } \\
\text { Attendance }\end{array}$ & 0.71 & $\begin{array}{c}\text { Early Word } \\
\text { Reading }\end{array}$ \\
\hline
\end{tabular}

Note. $95 \% \mathrm{Cl}[2.33,13.74]$, size of mediated effect ranges from .09 to .52 .

-Full-Day Kindergarten children had fifth grade reading scores 6.22 scale score points higher than Half-Day Kindergarten children.

\begin{tabular}{|c|c|c|c|c|}
\hline $\begin{array}{l}\text { Full-Day } \\
\text { Attendance }\end{array}$ & 0.76 & $\begin{array}{l}\text { Early Word } \\
\text { Reading }\end{array}$ & 8.22 & 5th Grade Reading \\
\hline
\end{tabular}

Note. $95 \% \mathrm{Cl}[1.86 .10 .58]$; size of mediated effect ranges from .07 to .43 .

Full-Day Kindergarten and SES

-Low-SES children in Full-Day Kindergarten had comparable odds of early word reading attainment as middle/high-SES peers.

$\cdot \chi^{2}(1, N=2,434)=0.76, p=.38,95 \% \mathrm{Cl}[0.47,1.33]$

However, low-SES children in Half-Day Kindergarten had significantly lower odds compared to middle/high-SES peers.

$\cdot \mathrm{OR}=2.46, \chi^{2}(1, \mathrm{~N}=2,330)=6.92, \mathrm{p}=.01,95 \% \mathrm{Cl}[1.26 .4 .80]$

- There were no significant differences on $1^{\text {st }}, 3^{\text {rd }}$, or $5^{\text {th }}$ grade reading scores between low- and middle/high-SES children who attained early word reading.

Early Word Readers: SES and Elementary Grade Reading

\begin{tabular}{lccc}
\hline & $B$ & $S E$ & $p$ \\
\hline $1^{\text {st }}$ Grade Reading & 4.12 & 3.03 & .18 \\
$3^{\text {rd }}$ Grade Reading & 5.12 & 2.69 & .06 \\
$5^{\text {th }}$ Grade Reading & 3.46 & 2.47 & .16 \\
\hline
\end{tabular}

$5^{\text {th }}$ Grade Reading

\section{DISCUSSION}

> The benefit of Full-Day Kindergarten can be maintained beyond kindergarten, provided children acquire early word reading skills by the end of kindergarten. These provided children acquire early word reading skills by the end of
children earned higher reading scores in $1^{\mathrm{st}}, 3^{\text {rd }}$, and $5^{\text {th }}$ grades.

$>$ Full-Day Kindergarten attendance helped low-SES children become comparable to middle/high-SES peers during kindergarten.

$>$ As well, SES differences were not present for reading in the elementary grades if children attained early word reading skills at the end of kindergarten.

$>$ Although children in Full-Day Kindergarten were more likely to attain early word eading, only $19 \%$ of all children attained this skill set.

Kindergarten programs should focus on fostering the component early word reading skills, particularly the more advanced skills including ending sounds and sight words. $>$ Full-Day Kindergarten programs should target children from low-SES families in order to improve their school readiness. 